\title{
3D PRINTING SUSTAINABILITY ISSUES, THE CASE OF MULTI MAILBOXES PRODUCTION
}

\author{
Athena Baronos ${ }^{1}$, Odysseas Manoliadis ${ }^{2}$ and Aristeidis Pavlidis ${ }^{2}$ \\ ${ }^{1}$ University of Western Macedonia Koila Kozanis 67100 \\ ${ }^{2}$ Democritus University of Thrace12 Vas Sofias Xanthi 67100
}

DOI: 10.46609/IJETSI.2020.v05i04.001 URL: https://doi.org/10.46609/IJETSI.2020.v05i04.001

\begin{abstract}
3D printing has been recognized as a productive and feasible innovation within the fields of progressed fabricating. In the past few years, a considerable research conducted to advance 3D printing for a better performance in manufacturing. However, the benefits of $3 \mathrm{D}$ printing from environmental perspective are still to be evaluated. In this paper in order to better evaluate the sustainability of 3D printing processes quantitatively and better guide the decision-makers, proposed a framework for 3D printing processes sustainability assessment as a novel system for decision making. In addition, for sustainability assessment Computer Aided Design (CAD) and Life Cycle Assessment (LCA) were utilized. A multiple mailboxes design is used as a case study for this to provide a comprehensive understanding of 3D printing for the public and provide a better guide for the future research. The results have shown that material waste can be significant reduced and also the supporting material based on product redesign.
\end{abstract}

Keywords: 3D Printing, AutoCAD, multi mailboxes

\section{INTRODUCTION}

At a fundamental level, 3D printing takes advanced representations of objects and makes them in physical shape by building up numerous layers of plastics, metals, powders, fluid tars, and other materials. Individuals regularly allude to $3 \mathrm{D}$ printing as added substance fabricating to differentiate it otherwise removing material to create an object. A major part of 3D printing's request is that it permits for an unprecedented degree of rapid prototyping and mass customization. Whereas media coverage of 3D printing has frequently centered on cheap plastic 3D printed products — such as Smartphone cases, dolls with people's faces, and other customized knickknacks - a few of the foremost vital progresses in 3D printing are taking put in trade applications. 
Since late 1984 the primary 3D printing shows up. In 1988 it is accessible to the open after been patented in 1986. Stereo Lithography Device (SLA) machine was created, a sustainable resolution to reduce waste and production cycle has come around (Bloomberg Business week, 2014). From the manufacture of complicated fly motor parts to basic mugs, 3D printing is being respected as an elective and more proficient way to create modern products. Statistics appear that the global market for 3D printing will be worth $\$ 16.2$ billion by 2021 , which is four times bigger than that of 2014 (Bloomberg Businessweek, 2014).

Taken as a whole, 3D printing is changing fabricating and reconfiguring supply chains around the world. It is changing the way customers get the items they require and moving control to people with special and unique preferences. Postal administrators and about each organization that works in shipping, conveyance, or other angles of coordinations ought to keep a really close eye on it

The Postal Service has an unmatched last-mile delivery network - no other organization covers as much territory as frequently and regularly as the Postal Service. It is often not cost effective for private delivery firms to make separate stops to deliver small, relatively inexpensive packages, particularly in rural areas. However, the Postal Service visits these locations nearly every day. Accordingly, other delivery firms often use the Postal Service for final delivery of many packages: Multi mailboxes offer the advantage in delivering packages is critical to benefiting also from the growth of 3D printing quality.

In this way holding a competitive advantage in materials efficiency and less processing procedures, the technological and economic benefits of 3D printing have been widely reported and documented, and it became especially popular in the US Mail in United States in the last decade. Web of Science suggests that more than 12 papers have been published from 2005-2015 within the US, and it still presents a trend of fast increase in the basic theory exploration and technology development. Although several survey about 3D printing have been documented, almost all of them are written on behalf of its categories, processes, quality and cost benefits or focus on environmental impact of rapid prototyping technologies before 2006, the environmental issue in terms of this new coming technology is still to be evaluated. 


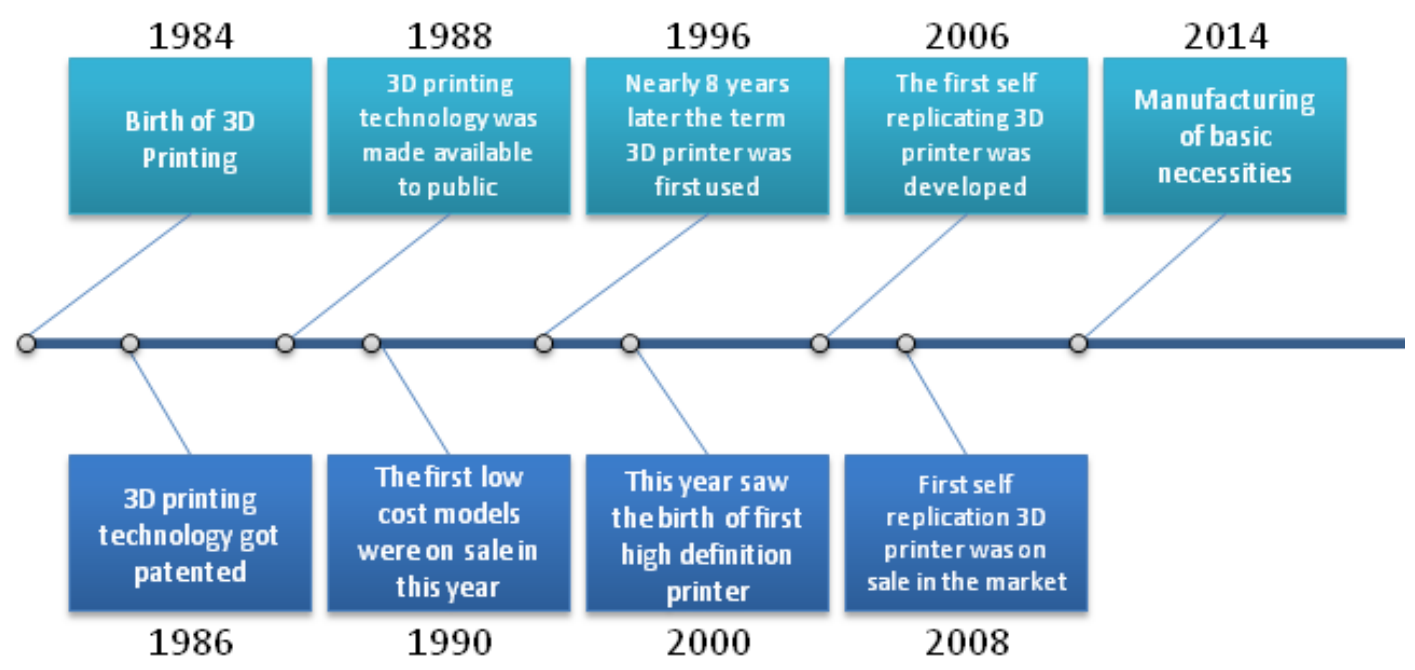

Figure 1.

Being different from conventional fabricating forms, 3D printing begins from modeling, going through printing and wrapping up, it saves the conventional forms of casting, producing and unpleasant machining without lessening the final part quality. Difference of processes in 3D printing and conventional fabricating is appeared in Table 1.

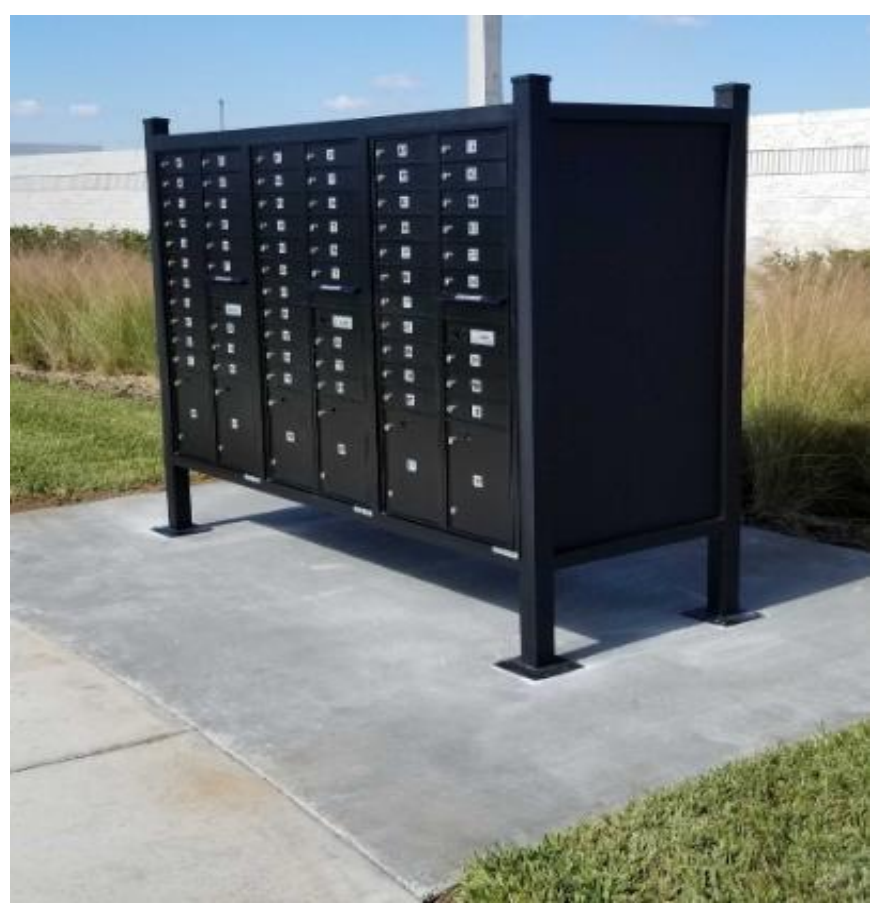

Figure 2: Traditional mailboxes 
International Journal of Engineering Technology and Scientific Innovation

ISSN: 2456-1851

Volume: 05, Issue: 04 "July-August 2020"

TABLE 1: Difference of Processes In 3d Printing and Traditional Manufacturing

\begin{tabular}{|l|l|l|}
\hline Items & 3D printing & $\begin{array}{l}\text { Traditional } \\
\text { manufacturing }\end{array}$ \\
\hline Manufacturing & Additive & Subtractive \\
\hline Efficiency & Higher & Lower \\
\hline Production Waste & Less & More \\
\hline Built time & Hours to days & Days to months \\
\hline Cost & Higher & Lower \\
\hline Life cycle & Shorter & Longer \\
\hline $\begin{array}{l}\text { Required } \\
\text { employees }\end{array}$ & Ordinary workers & Skillful workers \\
\hline
\end{tabular}

The public opinion is divergent about the sustainability of 3D printing, but what is the objective situation of the environmental impact of 3D printing at the present and how to assess the natural affect of 3D printing from a scientific way could be a issue worth examining. This paper outlined the sustainability of 3D printing through summarizing and analyzing published research. In the interim, a scientific way to assess the environmental impact of 3D printing is presented within the future viewpoint combined with the current research subject. This paper presents the relative research to be used in a framework for 3D printing processes sustainability assessment.

\section{SUSTAINABILITY SURVEY OF 3D PRINTING}

Therefore in order to present the sustainability of 3D printing and to illustrate the circumstance of distinctive 3D printing strategy, a study of recent papers and reports about sustainability analysis of 3D printing from Google Scholar and Web of Science is conducted, among the existing publications. These have been chosen and separated into two categories (Positive and Negative) alluding to environmental impact of 3D printing.

\subsection{Environmental Impacts}

\subsubsection{Positive}

Material waste is significant reduced supporting material which is utilized to create the progressively extraordinary geometries conceivable and therefore able to be reused in raw material after 3D printing is wrapped up (Reeves, 2007). The cumulative energy demand of fabricating polymer items can be decreased by 41-64\% with existing low-cost 3D printers Reeves (2007). Also according to Kreiger and Pearce (2013) packaging which are basic amid the conventional fabricating forms can be simplified or shortened in 3D printing. Additionally, the environmental impact can be diminished by scaling back or eliminating complex supply chains 
(Campbell et al, 2014) Mani et al (2014) claimed that additive manufacturing fabricating is more economical alternative since it requires no specialized tooling or installations and competent to make on-demand save parts, reducing or eliminating inventory.

\subsubsection{Negative}

A negative impact is that 3D printing waste is not necessarily recyclable (Rydberg, 2012). The foremost well known fabric utilized for 3D printers is plastic fiber. Whereas this plastic is high quality and generally cheap, its byproduct ends up in landfills. Essentially, a program at MIT found that laser direct metal statement employments hundreds of times the power as conventional machines. Also 3D printing strategies are not necessarily less inefficient, additionally their waste isn't essentially recyclable.

This practice contradicts any environmental movement to decrease our dependence on plastic. In order for broad 3D printing to work within the industry, the byproduct must be reused. Another issues with respect to the utilize of plastic is its energy use (Yoon et al 2014 ).Some say that expansive sum of electrical energy will be expended. A study done at Loughborough College found that 3D printers consume almost 50 to 100 times more electricity than infusion molding when making aproductof the same weight (Faludi et al, 2015).

Kurman (2013) reported that a huge sum of electrical energy will be expended will be consumed during the 3D-printing process as high as 50 to 100 times more than infusion molding (Another allegation is that unfavorably $3 \mathrm{D}$ printing influence the environment and human wellbeing

Since 3D printing processes are using ABS and PLA cartridge it will generate $1.61 \times 1010$ ea/min and 4.27-4.89 $\times 108 \mathrm{ea} / \mathrm{min}$ cartridge, which are adversely affect the environment and human health Kim et al (2015).3D printing processes using ABS and PLA cartridge will generate $1.61 \times 1010 \mathrm{ea} / \mathrm{min}$ and $4.27-4.89 \times 108 \mathrm{ea} / \mathrm{min}$ cartridge, which are adversely affect the environment and human health Kim et al (2015).

Table 1: Summary of positive and negative impacts of 3D printing

\begin{tabular}{|l|l|}
\hline Positive & Negative \\
\hline material waste is significant reduced & waste is not necessarily recyclable \\
\hline material able to be recycled into raw material & $\begin{array}{l}\text { large amount of electrical energy will be } \\
\text { consumed }\end{array}$ \\
\hline akingof the increasingly exotic geometries possible & $\begin{array}{l}\text { printing processes using ABS and PLA } \\
\text { cartridge will adversely affect the environment } \\
\text { and human health }\end{array}$ \\
\hline
\end{tabular}


Volume: 05, Issue: 04 "July-August 2020"

\begin{tabular}{|l|l|}
\hline packaging processes can be simplified &, \\
\hline Eliminates complex supply chains & \\
\hline Requires no specialized tooling or fixtures & \\
\hline
\end{tabular}

Conclusions about sustainability of 3D printing changes beneath diverse circumstances. Previous literature review shows that diverse strategies and materials utilizing in 3D printing innovation will different point of view in environmental impact assessment Kim et al (2015). A reasonable conclusion is that the environmental impact of 3D printing is case-by-case depending on particular circumstances.

\subsubsection{Social Economic}

Sustainability covers not only environmental aspect, it also involved with local economy (new employment positions) and social aspects.

An Update on 3D Printing and the Postal Service - Mail Boxes

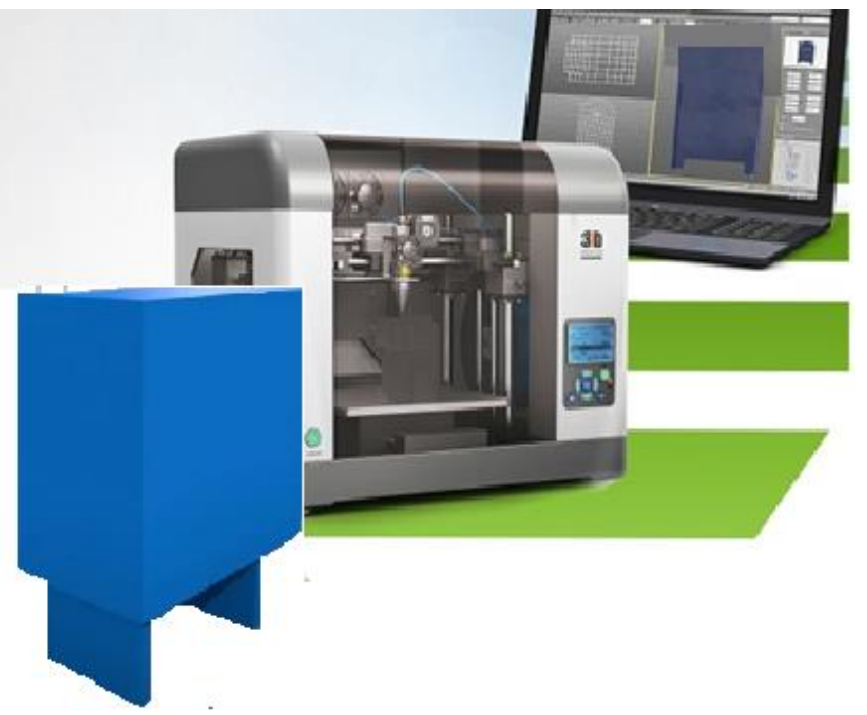

Figure 3: An Update on 3D Printing and the Postal Service - Mail Boxes

3D printing is leading to dramatic changes in the fields of manufacturing and logistics of postal services, with major implications for postal operators and other transportation and delivery companies. In a July 2014 white paper, If It Prints, It Ships: 3D Printing and the Postal Service, the OIG described how the rise of 3D printing could significantly benefit the Postal An Update on 3D Printing and the Postal Service, the OIG describes developments in 3D printing and the logistics marketplace and examines what these changes could mean for the Postal Service. 


\section{METHODOLOGY}

A framework for 3D printing processes sustainability assessment and improvement is proposed in this section. Product CAD is the first step in 3D printing processes, any decision related to the printing process, like materials selection as well as product structure (geometry change and assembly adjustment) will affect the sustainability of the final part. The final product CAD file is composed by the selection of different characteristics that are processed during such as the CAD stage. The essence of the method is to realize the integration of Life Cycle Assessment (LCA) and product Computer Aided Design (CAD) process. The general structure of proposed framework is shown in Figure 3.

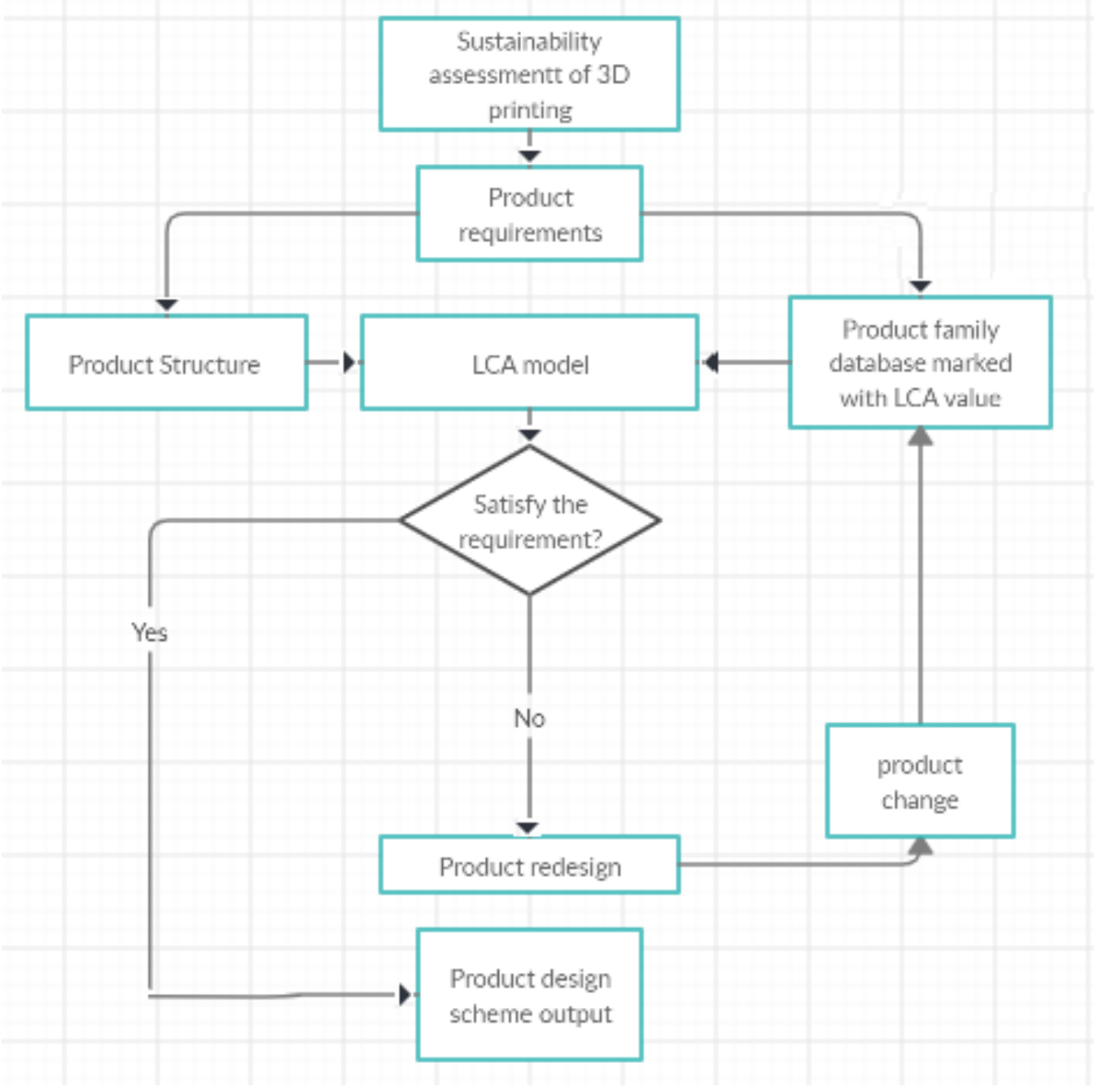

Figure 4: The decision-making procedure 
The major procedures of the framework including four steps that are listed as follows:

- Step 1. Construction of product CAD-LCA model. With product LCA method, environmental impact of each product characteristics. Once the product CAD is finished, with the marked LCA is assessed.

- Step 2 A Comparison to requirements is used to decide if the requirements are satisfied.

- Step 3 the design process should follow the basic principle that the geometrical feature after redesign should change accordingly to product change and different material/product should be used that imposes a new LCA value.

- Step 4 is an iteration procedure is followed until the product and its corresponding structure satisfies the requirement.

A product design scheme output of using the above framework for multiple mailboxes is presented. Fig. 5 shows the structure and dimensions of the multi mailbox Figures 6-9 show some parts used to assembly the final solution.

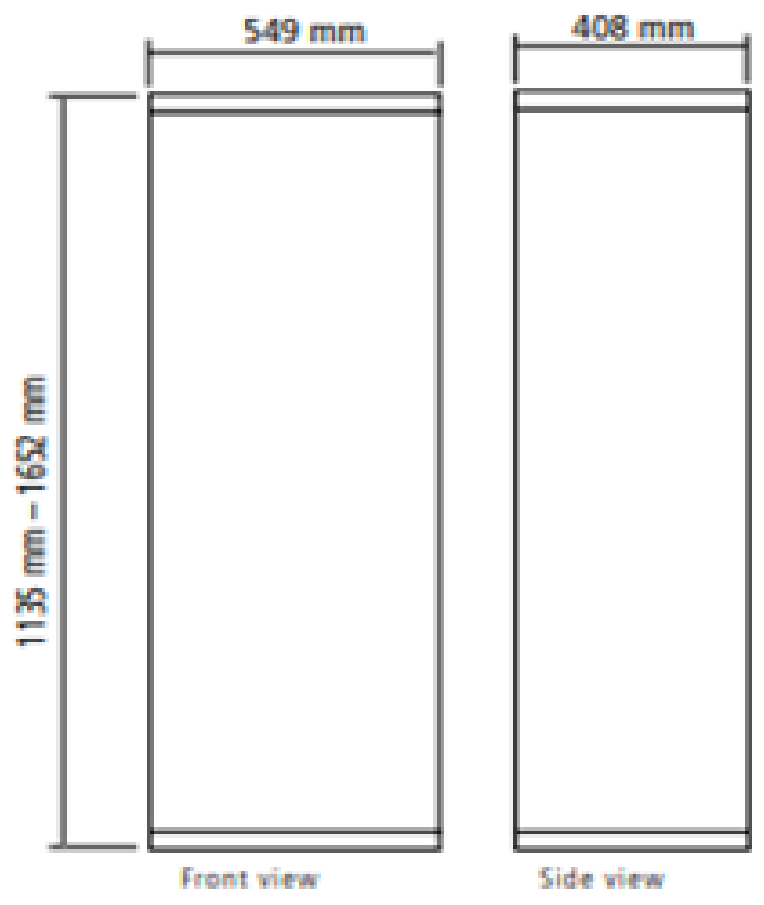

Figure 5: Multi mailbox 

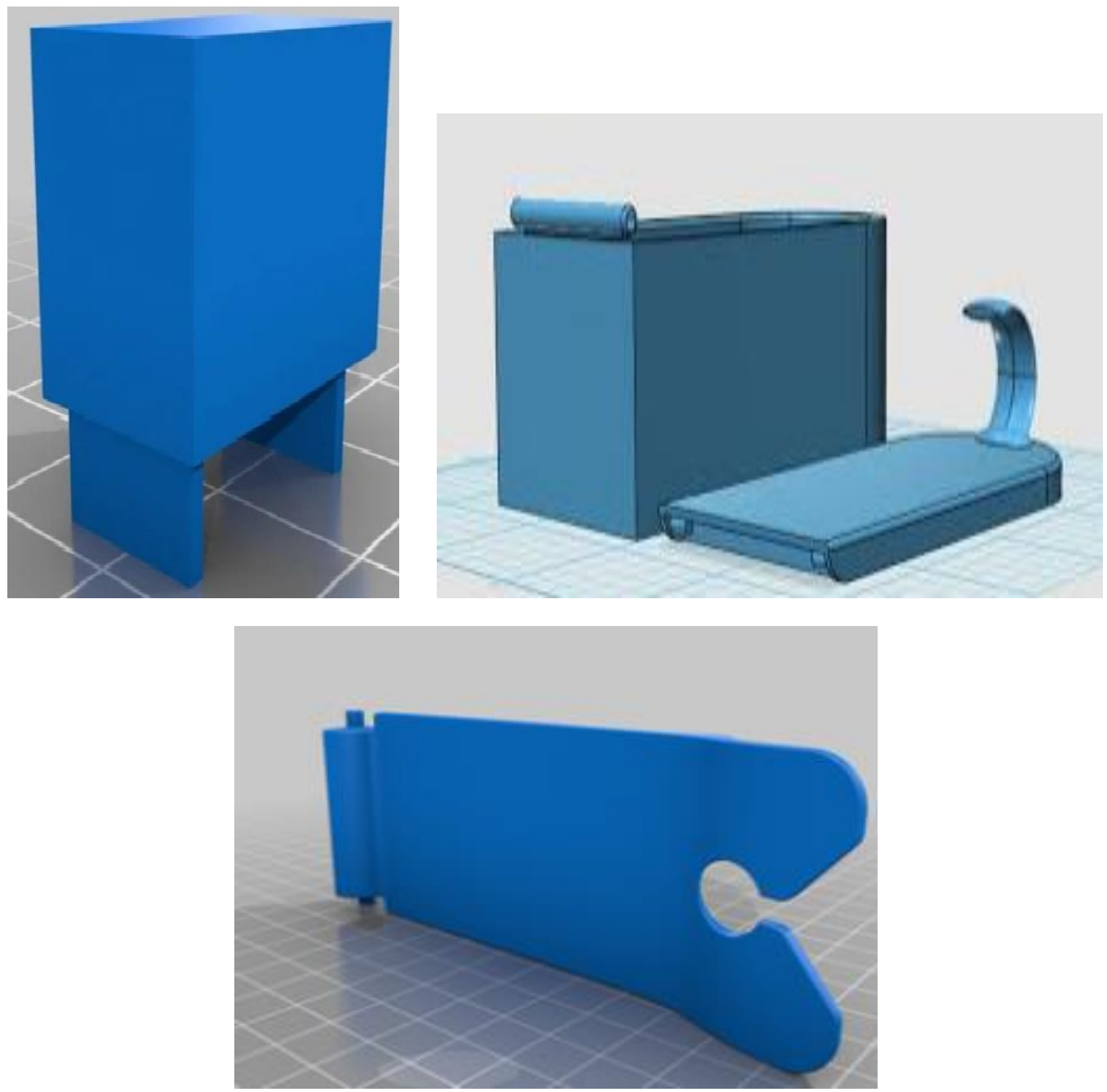

Figure 6: Components of mailboxes produced with 3D printing

\section{CONCLUSIONS}

The sustainability evaluation for 3D printing as a modern coming innovation is vital and it'll offer assistance to supply advancement openings for the modern item architects. The sensible conclusion is that environmental impact of 3D printing is case-by-case depending on particular circumstances.

In order to better evaluate the sustainability of 3D printing processes quantitatively and better guide the decision-makers, this paper proposed a framework for 3D printing processes sustainability assessment.

The integration of product CAD and LCA can realize the improvement in the early design stage, which is an essential step for 3D printing With the help of professional and public databases, 
International Journal of Engineering Technology and Scientific Innovation

ISSN: 2456-1851

Volume: 05, Issue: 04 "July-August 2020"

quantitative analysis for sustainability assessment of 3D printing become feasible through CAD and it can help to track and document the environmental impact in each life cycle stage and major contributing process and assembly. In the case of multiple mailboxes production being able to provide lightweight and cost effective designs, 3D printing is contributing to the application in components fabrication. As mentioned before in this paper, different 3D printing processes may generate totally different result referring to its environmental impact. It is not only relative to various processing principle, but also involved in the products itself. Some of the materials currently used in 3D printing will generate negative environmental emissions during the forming processes. The proposed framework for multiple mailboxes is an environmental evaluation model for 3D printing is helpful for its Eco design before the impletion of the final printing processes. It enables to build complex designs that are otherwise unattainable, or too expensive or labor-intensive to create by conventional construction means. This can allow for a lot more innovation and creativity in the commercial construction space.

\section{ACKNOWLEDGEMENT}

This paper is a byproduct of the scientific program "Design of Multiple Mailboxes" of the University of Western Macedonia.

\section{REFERENCES}

Bloomberg Businessweek, (2014): 3D printing, materials \& services: global market size 20142018, May 19 - May 25, 2014, page S4. http://www.statista.com/statistics/315363/globalmarket- for-3d-priting-and-services/

Campbell, T., Williams, C., Ivanova, O., Garrett, B., (2011): Could 3D Printing Change the World? Technologies, Potential, and Implications of Additive Manufacturing, strategic foresight report, Atlantic Council.Faludi, J., Bayley, C., Bhogal, S., Iribarne, My., (2015): Comparing environmental impacts of additive manufacturing vs traditional machining via life-cycle assessment, Rapid Prototyping Journal, Vol. 21 No. 1,

Kim, Y., Yoon, H.S., Ham, S., Park, J., Kim, S.H., Kwon, O, Tsai, P.J., (2015): Emissions of Nanoparticles and Gaseous Material from 3D Printer Operation, Environmental Science and Technology, Vol. 49, No. 20, pp. 12044-12053.

Kreiger, M. and Pearce. J. M., (2013): Environmental Life Cycle Analysis of Distributed ThreeDimensional Printing and Conventional Manufacturing of Polymer Products, ACS Sustainable Chemistry \& Engineering, Vol. 1, pp. 1511-1519. 
Kurman, M. \& Lipson, H. (2013): Is Eco Friendly 3D Printing a Myth? Triple Helix Innovation and Cornell University. http://www.livescience.com/38323-is-3d-printing-ecofriendly. html.

Mani, M., Lyons, K.W., Gupta, S.K., (2014): Sustainability Characterization for Additive Manufacturing, Journal of Research of the National Institute of Standards and Technology, Vol. 119, pp. 419- 428.

Reeves, P., (2009): Additive Manufacturing - A supply chain wide response to economic uncertainty and environmental sustainability, Econolyst Limited, The Silversmiths, Crown Yard, Wirksworth, Derbyshire, DE4 4ET, UK.

Rydberg, H., (2012): What is the environmental impact of 3D printing? Quora.https://www.quora.com/What-is-the-environmental-impact of-3D-printing

Yoon, H.S., Lee, J.Y., Kim, H.S., Kim, M.S., Kim, E.S., Shin, Y.J., Chu, W.S., Ahn, S. H., (2014): A Comparison of Energy Consumption in Bulk Forming, Subtractive, and Additive Processes: Review and Case Study, International journal of precision engineering and manufacturing green technology, Vol. 1, No. 3, pp. 261-279. 